\title{
SELEÇÃO INDIRETA EM AVEIA PARA O INCREMENTO NO RENDIMENTO DE GRÃOS
}

\author{
INDIRECT SELECTION IN OAT TO IMPROVE GRAIN YIELD
}

\author{
Eduardo Caierão $^{1}$ Fernando Irajá Félix de Carvalho $^{2}$ Marcelo Teixeira Pacheco $^{3}$ \\ Claudir Lonrecetti ${ }^{4}$ Volmir Sérgio Marchioro ${ }^{4}$ José Gonzales Silva ${ }^{4}$
}

RESUMO

Os diferentes caracteres de importância econômica para a cultura da aveia estão correlacionados entre si em magnitude e sentido variado. Tal fato implica que a seleção realizada sobre um caráter pode proporcionar alterações em outros, cujo resultado pode ou não ser de interesse. Assim, a quantificação dos efeitos diretos e indiretos da seleção de um ou vários caracteres sobre outros é de fundamental importância para orientar programas de melhoramento em que se tenham constituições genéticas que reúnam atributos favoráveis, constituindo-se no objetivo do trabalho. Foram avaliadas 58 linhagens de aveia, em Pelotas, em delineamento de blocos ao acaso com três repetições, sobre as quais foram realizadas avaliações fenotípicas, que foram utilizadas para a determinação dos coeficientes de correlação simples entre as variáveis. A partir desses coeficientes, aplicou-se o procedimento de análise de trilha sobre a variável rendimento de grãos. De acordo com os resultados obtidos, nenhuma variável analisada apresentou efeito direto sobre o rendimento de grãos semelhante ao coeficiente de correlação fenotípico total, demonstrando a existência de outras características influenciando, tanto na magnitude, como no sentido da correlação, impedindo a seleção isolada sobre um caractere visando ao rendimento de grãos. O caráter peso de panícula apresentou a maior correlação positiva com o rendimento de grãos, ao passo que os caracteres estatura de planta e ciclo apresentaram os menores coeficientes de correlação, o que dificulta a seleção indireta para rendimento de grãos por essas variáveis. Os caracteres número de grãos e peso de grãos, embora positivos e contribuindo para a determinação do peso de panícula, apresentaram correlação intermediária com o rendimento de grãos. Assim, considerar os efeitos do peso de panícula, número de grãos e peso de grãos parece ser a melhor estratégia para seleção indireta visando ao rendimento de grãos em aveia.
Palavras-chave: Avena sativa, seleção indireta, análise de trilha, componentes, rendimento.

\section{SUMMARY}

Different traits of economic importance for oat are correlated to each other in magnitude and varied sense. Such fact implies that the selection on a character can provide changes in the other, whose result can be or not interesting. Thus, the quantification of direct and indirect selection effects of one or several traits on others are of fundamental importance to guide improvement programs, representing the objective of this paper. 58 oat genotypes were evaluated, in Pelotas, RS, Brazil, in random block design with three replicates, on which phenotypic evaluations were conducted. These data were used to determine the simple correlation coefficients among variables. Starting from these coefficients, the path analysis procedure was applied on grain yield trait. In agreement with the obtained results, no analyzed variable presented direct effect on the grain yield similar to the phenotypic correlations coefficient, showing the existence of another traits influencing both in the magnitude and in the sense of the correlation, preventinng isolated selection on grain yield. Panicle weight showed the highest positive correlation with grain yield. However, stature and head date showed lower correlation coefficients, what makes difficult the indirect selection for grain yields. Grain number and grain weight, although positive and contributing to determine panicle weight, showed intermediary correlation with grain yield. Thus, to consider the effects of panicle weight, grain number and grain weight seems to be the best strategy for indirect selection of grain yield in oat.

Key words: Avena sativa, indirect selection, path analysis, yield components.

\footnotetext{
${ }^{1}$ Engenheiro Agrônomo, estudante do Curso de Pós-graduação em Agronomia da Universidade Federal de Pelotas (UFPel), Pelotas, RS - Bolsista da Capes. E-mail: mnec@terra.com.br.

${ }^{2}$ Engenheiro Agrônomo, PhD., Professor da Faculdade de Agronomia Eliseu Maciel (UFPel), Departamento de Fitotecnia, Campus Universitário, CP 354, 96001-970, Pelotas, RS. Pesquisador do CNPq. Autor para correspondência.

${ }^{3}$ Engenheiro Agrônomo, Mestre, Professor do Departamento de Plantas de Lavoura, Faculdade de Agronomia, Universidade Federal do Rio Grande do Sul.

${ }^{4}$ Aluno do Curso de Graduação em Agronomia da UFPel.

Recebido para publicação em 16.12.99. Aprovado em 30.08.00
} 


\section{INTRODUÇÃO}

A cultura da aveia representa uma alternativa promissora para a estação fria na região sul do Brasil, principalmente pela necessidade de renda nesse período de cultivo, e adaptação ao manejo de rotação de culturas, com destaque a sua inclusão no sistema de semeadura direta. Anualmente, em torno de 200.000ha de aveia são cultivados no sul do Brasil, sendo que grande parte dessa área é ocupada com aveia preta (Avena strigosa L.), com finalidade de cobertura do solo e produção de forragem. Por outro lado, os maiores esforços da pesquisa têm sido realizados com aveia branca (Avena sativa L.), cujo destino principal é a produção de grãos para a alimentação humana ou animal, embora seja também empregada na produção de forragem, silagem, feno, para cobertura do solo e matéria prima para indústria. Considerável progresso tem sido obtido no rendimento de grãos, assim como em outros caracteres agronômicos em aveia desde a implantação dos programas de melhoramento no sul do Brasil, promovendo o lançamento de 32 cultivares de aveia branca (FEDERIZZI et al., 1997; BARBOSA NETO et al., 1999).

Para que genótipos superiores estejam sempre à disposição dos produtores, é indispensável uma seleção eficiente, que muitas vezes pode ser trabalhosa e demorada, quando realizada diretamente sobre o caráter (GRAVOIS \& McNEW, 1993; FALCONER \& MACKAY, 1997). Essa dificuldade pode ser superada pela seleção de populações a partir de seus componentes de rendimento e outros caracteres adaptativos que, indiretamente, elevam o rendimento de grãos, representando uma boa alternativa de seleção. A seleção indireta, no entanto, exige a condição de alta correlação entre a variável que está sob seleção e a variável objetivo, além de uma herdabilidade elevada do caráter a ser selecionado (FALCONER \& MACKAY, 1997).

Estudos de correlação simples não permitem tirar conclusões sobre causa e efeito entre as variáveis, mas apenas indicam uma associação entre elas (VENCOVSKY \& BARRIGA, 1992). A partir dessa lacuna, LI (1981) propôs um método próprio que investiga essas relações causais, denominado de análise de trilha ou "Path analysis". Conforme SAMONTE $\boldsymbol{e t}$ al. (1998), a principal vantagem da análise de trilha é permitir a fragmentação do coeficiente de correlação em componentes, um sendo o coeficiente de trilha propriamente dito, avaliando a influência direta da variável independente sobre a variável resposta e outro, que demonstra os efeitos indiretos da variável independente sobre a variável resposta, através de outras variáveis. Assim, a análi- se de trilha tem sido utilizada por melhoristas para assistir a identificação de características que possam ser úteis como critérios de seleção para o rendimento de grãos, tanto em aveia como outras culturas.

Estudos realizados por CHAPKO \& BRINKMAN (1991) indicaram correlação de 0,7 entre o peso de panícula e o rendimento de grãos, além de valores intermediários a altos de herdabilidade para o caráter número de espiguetas por panícula e número de grãos. Conforme ISLAM et al.(1985), da mesma forma que para a aveia, os componentes do rendimento de grãos em trigo apresentaram herdabilidade moderada, com boas perspectivas para a sua utilização como critério de seleção indireta, visando ao rendimento de grãos.

O presente trabalho teve como objetivo identificar uma estratégia eficiente de seleção indireta para rendimento de grãos em aveia, a partir de seus componentes do rendimento.

\section{MATERIAL E MÉTODOS}

Setenta e seis linhagens de aveia (Avena sativa L.) foram introduzidas através de um convênio coordenado pela Quaker (EUA), no ano de 1998 na área experimental do Setor de Fitomelhoramento, no Centro Agropecuário da Palma, em Pelotas. De todos os genótipos, somente 57 foram utilizados nas avaliações, devido a melhor adaptação às condições do sul do Estado do Rio Grande do Sul. Excetuando o rendimento de grãos, as variáveis analisadas foram divididas em dois grupos: a) variáveis de importância primária sobre o rendimento - número de grãos por panícula (NG), peso das panículas (PP) e peso de mil grãos (PMG); e b) importância secundária sobre o rendimento - estatura de planta (EP) e o ciclo, nos subperíodos da emergência à maturação (DEM), da emergência ao florescimento (DEF) e da floração à maturação (DFM).

O delineamento experimental utilizado foi blocos ao acaso, com 3 repetições. A semeadura do experimento foi realizada em julho, com densidade de 300 sementes por $\mathrm{m}^{2}$. A unidade experimental foi constituída de 2 linhas, de $2,5 \mathrm{~m}$ de comprimento e $0,2 \mathrm{~m}$ entre linhas, com espaçamento de $0,4 \mathrm{~m}$ entre unidades experimentais. A adubação do ensaio foi realizada de acordo com a COMISSÃO DE FERTILIDADE DO SOLO do RS e SC (1995), a partir da análise de solo. A adubação de cobertura foi realizada 20 dias após a emergência das plântulas, na forma de uréia, na quantidade de $100 \mathrm{~kg} / \mathrm{ha}$. O controle de invasoras foi realizado manualmente.

As determinações das diversas variáveis foram feitas individualmente segundo a seguinte metodologia: rendimento de grãos (RG) - o rendi- 
mento de grãos foi determinado a partir da colheita das 2 linhas de cada genótipo no período de maturação plena. Os grãos foram trilhados e desaristados; peso de panículas (PP) - de cada genótipo foram colhidas 10 panículas aleatórias. Foi considerado uma bordadura de $0,5 \mathrm{~m}$ em os ambos lados da unidade experimental, e foram colhidas 5 plantas ao acaso por linha. As panículas foram colhidas no estágio de maturação fisiológica e posteriormente pesadas; número de grãos por panícula $(\mathrm{NG})$ - foi obtido a partir das 10 panículas colhidas. Essas panículas foram trilhadas e desaristadas, contando-se os grãos e dividindo-se o total pelo número de panículas. Além disso, determinou-se o peso desses grãos; peso de mil grãos (PMG) - o peso de mil grãos foi obtido pelo quociente entre o peso dos grãos e o número de grãos, ambos obtidos das 10 panículas colhidas. $\mathrm{O}$ valor de um grão foi então transformado para mil grãos; estatura de planta (EP) - determinada 21 dias após a emergência das panículas (floração plena), medindo-se da base da planta até o ápice da panícula. Foram realizadas 3 medições dentro da unidade experimental e realizada a média dos resultados obtidos; ciclo total (DEM) - calculado pela diferença de dias entre a emergência das plântulas e a data de sua maturação; subperíodo da emergência à floração (DEF) - calculado pela diferença de dias entre a emergência das plântulas e a floração plena do genótipo (50\% de panículas totalmente emergidas da bainha); subperíodo da floração à maturação (DFM) - calculado pela diferença de dias entre a floração plena do genótipo e a maturação.

A análise estatística consistiu da obtenção dos coeficientes de correlação de Pearson entre todas as variáveis analisadas, conforme STEEL \& TORRIE (1980). O caráter que apresentou maior coeficiente de correlação com o rendimento foi submetido também à análise de trilha, considerando o caráter escolhido como variável dependente e os demais como variáveis independentes, ignorando, nessa última análise, o rendimento de grãos.

As análises foram executadas pelo programa computacional GENES, desenvolvido pela Universidade Federal de Viçosa (CRUZ \& REGAZZI, 1997a).

\section{RESULTADOS E DISCUSSÃO}

A partir dos coeficientes de correlação, observa-se que as variáveis primárias, número de grãos (NG), peso de panícula (PP) e peso de mil grãos (PMG), apresentaram tendência a associações positivas com o rendimento de grãos, ao passo que as secundárias, dias da emergência à maturação (DEM) e dias da emergência à floração (DEF), caracterizaram-se por tendência negativa (Tabela 1). A amplitude das estimativas de correlação entre as variáveis, em valores absolutos, foi de 0,0120 a 0,8621, respectivamente para PMG x NG e NG x PP. A não correlação significativa observada entre PMG e NG pode ser explicada pela independência dessas variáveis, já que, dificilmente, um programa de melhoramento alcança elevado número de grãos com alto peso. Conforme VENCOVSKY \& BARRIGA (1992), coeficientes de correlação baixos não representam falta de associação entre as características, mas sim, inexistência de causa e efeito. Semelhantemente a YIOSHIDA (1981), que encontrou uma relação compensatória pequena entre número e peso de panícula em arroz, o número e peso de grãos em aveia também comportaram-se dessa maneira.

Como o rendimento de grãos é determinado pela multiplicação de seus componentes, ou seja, número de plantas/unidade de área, número de grãos e peso de grãos, a associação entre eles é perfeitamente justificada. O coeficiente de correlação linear entre PP e RG $(0,72)$ fornece boas perspectivas de seleção indireta via PP, principalmente levando em consideração que os grãos representam 80

Tabela 1 - Coeficientes de correlação de Pearson entre os caracteres rendimento de grãos (RG), peso de mil grãos (PMG), número de grãos (NG), peso de panícula (PP), estatura de planta (EP), dias da emergência à floração (DEF), dias da emergência à maturação (DEM) e dias da floração à maturação (DFM), em 58 genótipos de aveia. Pelotas-RS, 2000

\begin{tabular}{|c|c|c|c|c|c|c|c|c|}
\hline Caracteres & RG & PMG & NG & PP & EP & DEF & DEM & DFM \\
\hline RG & 1 & $0,3609 * *$ & $0,6164 * *$ & $0,7190 * *$ & $0,1311 \mathrm{~ns}$ & $-0,3464 * *$ & $-0,2834 * *$ & $0,0611 \mathrm{~ns}$ \\
\hline PMG & & 1 & $-0,0120 \mathrm{~ns}$ & $0,4043 * *$ & $-0,1847 \mathrm{~ns}$ & $-0,1525 \mathrm{~ns}$ & $-0,2260 \mathrm{~ns}$ & $-0,0080 \mathrm{~ns}$ \\
\hline NG & & & 1 & $0,8621 * *$ & $0,2884 *$ & $-0,1228 n s$ & $-0,2898 *$ & $-0,1182 \mathrm{~ns}$ \\
\hline PP & & & & 1 & $0,2025 \mathrm{~ns}$ & $-0,1475 \mathrm{~ns}$ & $-0,2244^{*}$ & $-0,0908 \mathrm{~ns}$ \\
\hline EP & & & & & 1 & 0,3093* & $-0,0691 \mathrm{~ns}$ & $-0,3600 * *$ \\
\hline DEF & & & & & & 1 & $0,4743^{* *} *$ & $-0,4264 * *$ \\
\hline DEM & & & & & & & 1 & $0,4937 * *$ \\
\hline DFM & & & & & & & & 1 \\
\hline
\end{tabular}

\footnotetext{
* = significativo pelo teste de t em nível de 5\% - ** = significativo pelo teste de $\mathrm{t}$ em nível de $1 \%$. $\mathrm{RG}=$ rendimento de grãos; $\mathrm{PMG}$ = peso de mil grãos; $\mathrm{NG}=$ número de grãos.

$\mathrm{EP}=$ estatura de planta; $\mathrm{DEF}=$ dias da emergência à floração.

$\mathrm{DEM}=$ dias da emergência à maturação; $\mathrm{DFM}=$ dias da floração à maturação. $\mathrm{PP}=$ peso de panícula.
}

Ciência Rural, v. 31, n. 2, 2001. 
a $85 \%$ do peso da panícula, diferente de outros cereais, em que o percentual é inferior.

Conforme CRUZ \& REGAZZI (1997b), a existência de correlações significativas é indicativo da viabilidade da seleção indireta para a obtenção de ganhos no caráter de maior importância econômica, que depende, também, diretamente da herdabilidade do caráter considerado. Nesse sentido, os caracteres secundários parecem ser inapropriados para a seleção indireta, mesmo que, por serem caracteres qualitativos, apresentem alta herdabilidade.

$\mathrm{Na}$ tabela 2, verifica-se as estimativas dos efeitos diretos e indiretos das variáveis analisadas sobre o RG. A maioria das variáveis analisadas apresentaram efeito direto sobre o rendimento de grãos com magnitude inferior ao coeficiente de correlação de Pearson, o que demonstrou existirem outras características influenciando, tanto em magnitude, como no sentido da correlação. Tal situação dificulta a seleção isolada de um caractere visando ao rendimento de grãos (VENKOVSKY \& BARRIGA, 1992). Assim, a utilização do caráter PP (de maior correlação linear com o rendimento) deve ser auxiliado por outras variáveis, principalmente os componentes do rendimento. $\mathrm{O}$ coeficiente de correlação encontrado entre PP e RG apresentou-se muito próximo ao encontrado por SAMONTE et al. (1998), que obtiveram valores de 0,72 para a mesma cultura. Para a seleção indireta, visando ao rendimento de grãos, o efeito do PP deve ser sempre considerado, podendo ser associado ao PMG e NG, devido ao efeito positivo observado na correlação $(0,21$ e 0,47 , respectivamente).

O coeficiente de determinação encontrado (59\%) indica que quase $60 \%$ no rendimento obtido é devido aos efeitos das variáveis analisadas. Tal coeficiente fica restrito a esses patamares devido ao caráter ser quantitativo, com grande número de genes de pouco efeito no caráter, apresentando variância ambiental considerável, reduzindo a sua herdabilidade.
Tabela 2 - Estimativas dos efeitos diretos e indiretos das variáveis peso de mil grãos (PMG), número de grãos (NG), peso de panícula (PP), estatura de planta (EP), dias da emergência à floração (DEF), dias da emergência à maturação (DEM) e dias da floração à maturação (DFM) sobre o rendimento de grãos (RG), em 58 genótipos de aveia. Pelotas-RS, 2000.

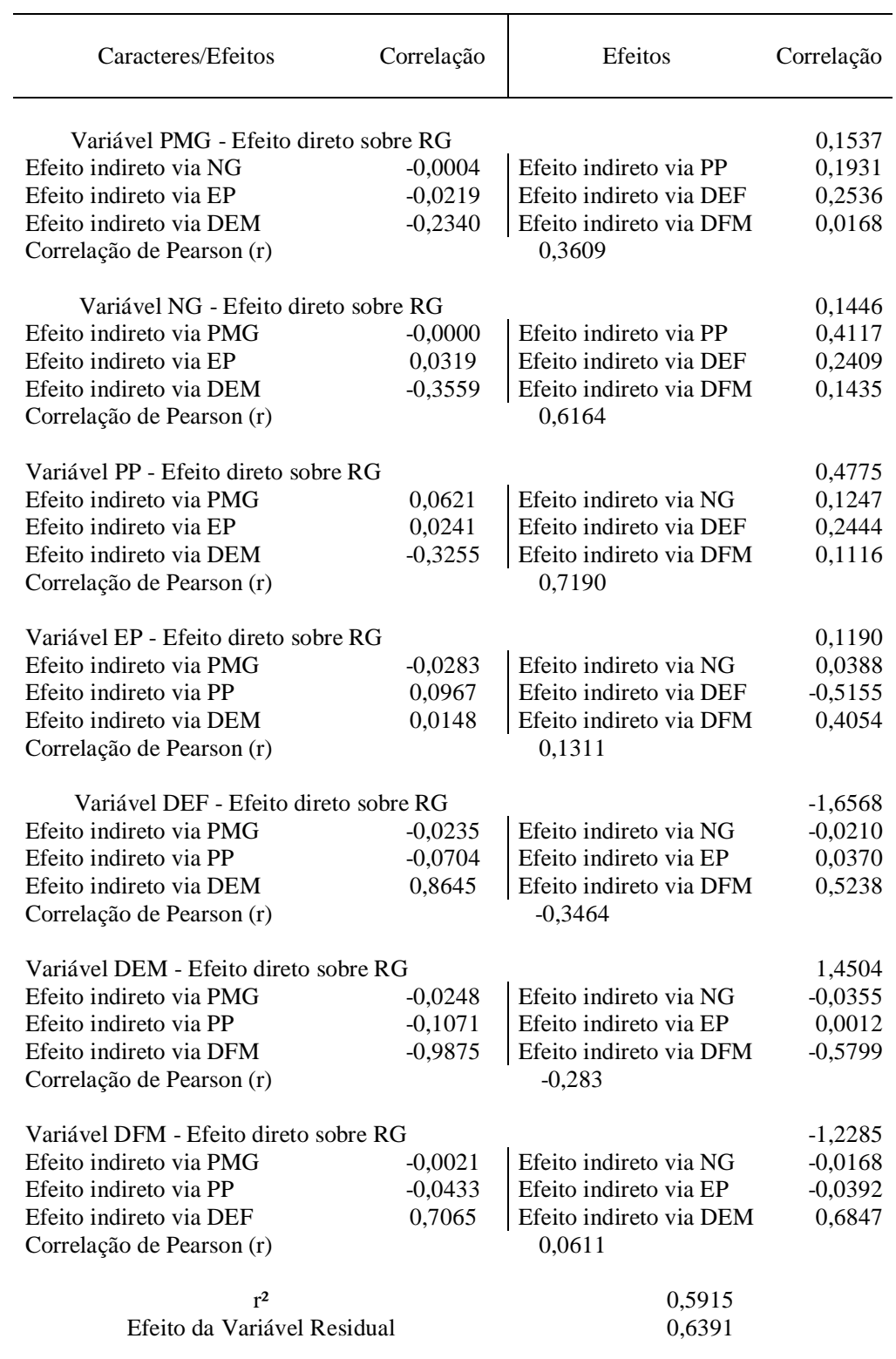

De maneira geral, os efeitos indiretos do NG e PMG foram baixos, por serem dependentes de outros caracteres e também muito influenciados pelo ambiente.

A seleção indireta para RG em função do NG e PMG deve ser baseada na associação de caracteres e não nos efeitos diretos de cada uma, já que suas estimativas diretas foram baixas, embora positivas. Os efeitos indiretos via $\mathrm{DEF}$, tanto da variável 
PMG, NG e PP, foram consideráveis, podendo ser utilizadas no momento da seleção. Nesse sentido, a seleção deve considerar o ciclo vegetativo dos genótipos, priorizando constituições genéticas com maior período até a floração, o que refletiria adicionalmente no sucesso da seleção indireta via componentes do rendimento.

A baixa correlação com o RG dos caracteres EP, DEF, DEM e DFM (Tabela 1) dificulta a possibilidade de seleção do caráter a partir das mesmas, quando se consideram os efeitos diretos e, na maioria dos efeitos indiretos via outras características, por apresentaram magnitude da estimativa inferior ao da variância residual. Seus efeitos indiretos poderão ser utilizados como auxiliares para a elevação da correlação por outro caractere. Surpreendentemente, a variável DFM apresentou baixa correlação com o RG, devido a um alto efeito direto negativo sobre o rendimento.

A decomposição dos efeitos das variáveis analisadas sobre o RG apontou o PP como a mais indicada para a seleção indireta, principalmente por seu efeito direto representar $(0,48)$ da correlação total $(0,72)$ da variável (Tabela 2). Assim, na tabela 3, estão apresentadas as estimativas dos efeitos diretos e indiretos das variáveis PMG, NG, EP, DEF, DEM e DFM, sobre o PP, para a determinação dos caracteres que mais contribuem para sua estimativa.

$O$ coeficiente de determinação geral $\left(r^{2}\right)$ encoraja a seleção a partir desse caractere, já que $91 \%$ da variação no peso de panícula é explicada pelo efeito das variáveis analisadas, com especial atenção para PMG e NG, que apresentaram, respectivamente, correlação de 0,40 e 0,86 (Tabela 3) com o peso de panícula. $\mathrm{O}$ efeito direto de PMG para a seleção sobre o peso de panícula ou a seleção associada com o DEF apresentaram-se como boas estratégias para a obtenção de elevado peso de

Tabela 3 - Estimativas dos efeitos diretos e indiretos das variáveis peso de mil grãos (PMG), número de grãos (NG), estatura de planta (EP), dias da emergência à floração (DEF), dias da emergência à maturação (DEM) e dias da floração à maturação (DFM) sobre o peso de panículas (PP), em 58 genótipos de aveia. Pelotas-RS, 2000.

Caracteres

Variável PMG - Efeito direto sobre PP

Efeito indireto via NG

Efeito indireto via EP

Efeito indireto via DEF

Efeito indireto via DEM

Efeito indireto via DFM

Correlação de Pearson (r)

Variável NG - Efeito direto sobre PP

Efeito indireto via PMG

Efeito indireto via EP

Efeito indireto via DEF

Efeito indireto via DEM

Efeito indireto via DFM

Correlação de Pearson (r)

Variável EP - Efeito direto sobre PP Efeito indireto via PMG

Efeito indireto via NG

Efeito indireto via DEF

Efeito indireto via DEM

Efeito indireto via DFM

Correlação de Pearson (r)

Variável DEF - Efeito direto sobre PP

Efeito indireto via PMG

Efeito indireto via NG

Efeito indireto via EP

Efeito indireto via DEM

Efeito indireto via DFM

Correlação de Pearson (r)

Variável DEM - Efeito direto sobre PP

Efeito indireto via PMG

Efeito indireto via NG

Efeito indireto via EP

Efeito indireto via DFM

Efeito indireto via DFM

Correlação de Pearson (r)

Variável DFM - Efeito direto sobre PP

Efeito indireto via PMG

Efeito indireto via NG

Efeito indireto via EP

Efeito indireto via DEF

Efeito indireto via DEM

Correlação de Pearson (r)

$\mathrm{r}^{2}$
Efeito da Variável Residual
Estimativa de Correlação com Peso de Panículas
0,4246

$-0,0024$

$-0,0093$

0,4838

$-0,5315$

0,0392

0,8633

$-0,0011$

0,0136

0,4594

$-0,8083$

0,3352

0,8621

0,0508

$-0,0781$

0,2321

$-0,9832$

0,0337

0,9472

0,2025

$-3,1597$

$-0,065$

$-0,1255$

0,0158

1,9631

1,2238

$-0,1475$

3,2936

$-0,0685$

$-0,2118$

0,0005

$-1,8833$

$-1,3548$

$-0,224$

$-2,8698$

$-0,0058$

$-0,1008$

$-0,0167$

1,3474

1,5549

$-0,0908$

0,9140

0,2932 panícula, já que a inclusão de outros caracteres, via seleção indireta de PMG, tendem a reduzir sua correlação com o PP, devido à direção contrária de suas

Ciência Rural, v. 31, n. 2, 2001. 
estimativas. A mesma situação pode ser observada para a variável NG.

\section{CONCLUSÃO}

A seleção indireta para rendimento de grãos a partir do peso de panícula, levando em conta o número de grãos e/ou peso de mil grãos, é a melhor estratégia de seleção indireta para a seleção de genótipos superiores em aveia.

\section{BIBLIOGRAFIA}

BARBOSA NETO, J.F., MATIELLO, R.R., CARVALHO, F.I.F., et al. Progresso genético no melhoramento da aveia no sul do Brasil. In: REUNIÃO DA COMISSÃO BRASILEIRA DE PESQUISA DE AVEIA, 19, Porto Alegre-RS, 1999. Resultados Experimentais... Porto Alegre : UFRGS, 1999. p.2326. $476 \mathrm{p}$

CHAPKO, L.B., BRINKMAN, M.A. Interrelationships between panicle weight, grain yield on grain yield components in oat. Crop Science, Madison, v.31, p.878-882, 1991

COMISSÃO DE FERTILIDADE DO SOLO DO RS E SC Recomendações de adubação e de calagem para os estados do Rio Grande do Sul e de Santa Catarina. 3.ed. Passo Fundo : SBCS-Núcleo Regional Sul, 1994. 221p.

CRUZ, C.D., REGAZZI, A.J. GENES: Aplicativo computacional em genética e estatística. Viçosa : UFV, 1997a. 442p.

CRUZ, C.D., REGAZZI, A.J. Modelos biométricos aplicados ao melhoramento genético. 2.ed. Viçosa : UFV, 1997b. 390p.
FALCONER, D.S., MACKAY, T.F. Introduction to quantitative genetics. 4.ed. Londres : Longman Group, 1997. 464p.

FEDERIZZI, L.C., MILACH, S.C.K., BARBOSA NETO, J.F., et al. Melhoramento genético de trigo e aveia no Brasil. In: ABREU, A.F.B., GONÇALVES, F.M.A., MARQUES JÚNIOR, O.G., et al. Simpósio sobre atualização em genética e melhoramento de plantas. Lavras : Universidade Federal de Lavras. Lavras, 1997. p.127-146.

GRAVOIS, K.A., McNEW, R.W. Genetic relationships among and selection for rice yield and yield components. Crop Science, Madison, v.33, p.249-252, 1993.

ISLAM, M.S., FAUTRIER, A.G., LANGER, R.H.M. Early generation selection in two wheat crosses. I. F2 single plant selection. Agriculture Research, v.28, p.313-317, 1985.

LI, C.C. Path analysis - a primer. 3ed. Pacific Grove : The Boxwood, 1981. 347p.

SAMONTE, S.O.P.B., WILSON, L.T., McCHUNG, A.M. Path analyses of yield and yield-related traits of fefteen diverse rice genotypes. Crop Science, Madison, v.38, p.1130-1136, 1998.

STEEL, R.G.D., TORRIE, J.L. Principles and procedures of statistics. New York : Macgraw-Hill, 1980. 418p.

VENCOVSKY, R., BARRIGA, P. Genética biométrica no fitomelhoramento. Ribeirão Preto : Revista Brasileira de Genética, 1992. 496p.

YOSHIDA, S. Fundamentals of rice crop science. Los Baños, Philippines : IRRI, 1981. 1512p.

Ciência Rural, v. 31, n. 2, 2001. 